\title{
FLAP DESIGN: COMPARISON OF WARD'S FLAP VERSUS MODIFIED WARD'S FLAP IN SURGICAL EXTRACTION OF IMPACTED MANDIBULAR THIRD MOLAR.
}

\author{
1. BDS, MSc \\ Department of Oral \& Maxillofacial \\ Surgery \\ LUMHS, Jamshoro. \\ 2. BDS \\ Lecturer \\ Department of Dental Materials \\ LUMHS, Jamshoro. \\ 3. BDS, FCPS \\ Associate Professor \\ Department of Oral \& Maxillofacial \\ Surgery \\ LUMHS, Jamshoro. \\ 4. BDS, MSc \\ Lecturer \\ Department of Oral \& Maxillofacial \\ Surgery \\ LUMHS, Jamshoro.
}

Correspondence Address:

Dr. Salman Shams

Department of Oral \& Maxillofacial

Surgery

LUMHS, Jamshoro.

Article received on:

28/08/2018

Accepted for publication:

13/11/2018

Received after proof reading:

$31 / 07 / 2019$

\section{Ashook Kumar ${ }^{1}$, Anny Memon ${ }^{2}$, Suneel Kumar Panjabi ${ }^{3}$, Salman Shams ${ }^{4}$}

ABSTRACT... To compare the Ward's Flap Versus Modified Ward's flap in relation to access, healing \& postoperative complications in surgical extraction of mandibular third molar impaction. Study Design: Comparative Cross Sectional. Setting: Department of Oral \& Maxillofacial Surgery LUMHS Jamshoro/Hyderabad: Period: March 2017 to November 2017. Materials and Methods: The history, clinical examination and radiographs (OPG and periapical) had done by team of researchers and recorded on proforma. After selection of patient into either group (Group A=Wards Flap, Group B Modified Wards), the surgical extraction was carried out under local anesthesia. For group A, a standard full thickness mucoperiosteal flap (ward's flap) was raised. The incision was given mesial to the impacted lower third molar. For group $B$, a standard full thickness mucoperiosteal flap (Modified ward's flap) was given mesial to second molar. At the end of the surgery, the flap design used for the extraction of impacted lower third molar tooth and the duration of each operation (from the first extraction maneuver to the completion of the last suture), Pain, Swelling and Trismus ${ }^{13}$ were recorded on the proforma. Every patient was called for follow up on the $3^{\text {rd }}$ day and $7^{\text {th }}$ day. Results: Mean age was found 27.93 years, with range of minimum 20 years and maximum 35 years. Male were found in the majority $72.3 \%$. Majority of the cases $51.5 \%$ were found with class B, in class A $37.5 \%$ and $10.9 \%$ were found with class $\mathrm{C}$. According to the impaction position $50 \%$ cases were in class I, and $50 \%$ cases were in class II. Preoperative pain measurement was done according VAS, $71.9 \%$ patients were found with mild pain, $9.4 \%$ were with moderate pain while $18.8 \%$ patients were without pain. Modified Wards flap showed good efficacy regarding duration of third molar extraction as compare to Ward's flap P-value 0.018 . Modified ward's flap had showed less postoperative pain as compare to ward's flap p-value 0.022 . No significant difference was found between both groups on $3^{\text {rd }}$ and $7^{\text {th }}$ postoperative day in Mouth opening. Conclusion: This study concluded that both ward's flap and modified ward's flaps showed good efficacy, while duration of surgery and postoperative pain were significantly less in the modified ward's flaps as compare to ward's flap. More large sample size studies are required to evaluate more accurate findings.

Key words: $\quad$ Flap, Mouth Opening, Pain, Surgical Extraction, Third Molar

Article Citation: Kumar A, Memon A, Panjabi SK, Shams S. Flap design: Comparison of ward's flap versus modified ward's flap in surgical extraction of impacted mandibular third molar. Professional Med J 2019; 26(8):1323-1327.

DOI: 10.29309/TPMJ/2019.26.08.3877

\section{INTRODUCTION}

Lower third molar extraction is the frequently performed practice in oral surgery and necessitates substantial preparation and ability in analysis and intraoperative as well as postoperative management. ${ }^{1}$ The extraction may range from relatively easy to extremely difficult depending on its location, depth, angulation, and density of bone. Regardless of degree of difficulty, the success depend primarily on correct preoperative assessment and planning, and on careful execution that comes with extensive training and experience. ${ }^{2}$

Although the prevalence of complications in relation to surgical procedure is low, surgeon must previously inform the patient for possible intraoperative and postoperative risks and complications. $^{3}$

Flap design is one of the most important factor which influence the severity of the complications, allowing for optimal visibility and access to impacted tooth. ${ }^{4}$ Flaps used preferably for third 
molar surgery are envelop flap and triangular flap. ${ }^{4}$ Modified Ward's flap is regarded as more conservative owing to adequate degree of tissue reflection, which has advantages like better accessibility and visibility especially in deep seated mandibular impactions. ${ }^{5}$

The third molar surgery in some case may be carried out simply by closed extraction method, and many cases involve open surgical procedures that comprise the raising of flap and removal of alveolar bone. ${ }^{6}$ The benefit of third molar surgery include the relief of pain, swelling, trismus, the prevention of caries, periodontal disease, prevention of pathological conditions such as abscess, cyst and pathological fracture. ${ }^{7}$ Several classification system have been established to estimate the surgical difficulty of removing lower third molar. ${ }^{8}$

The difficulty index consist of three components; Angulation (in relation to long axis of second molar [mesioangular, distoangular, horizontal], Depth (in relation to occlusal plane [Class $A, B, C]$ ) and position (in relation to vertical ascending ramus [Class I,II \& III]). ${ }^{9}$ The occurrence of these indices are associated with several factors which include age, gender, and general health of patient, the smoking status, use of oral contraceptive (in case of females), and surgical technique used along with the preferred flap design. ${ }^{10}$

The aim of this study is to evaluate the less aggressive technique Ward's versus Modified Ward's flap with respect to less post-operative complications in removal of lower third molar.

\section{DATA COLLECTION PROCEDURE}

An informed and written consent was taken before enrolment of study. The demographic and clinical parameters like age, gender, medical history, procedure of removal of tooth were identified and recorded in proforma.

The history, clinical examination and radiographs (OPG and periapical) had done by team of researchers and recorded on proforma. Preoperative assessment of pain [using VAS from zero (no pain) to 10 (worst pain imaginable)], degree of swelling [using criteria published by Amin \& Laskin] and limited mouth opening [using millimeter ruler (measuring the maximum distance between maxillary and mandibular central incisor)] associated with impacted mandibular third molar was performed. ${ }^{11}$

A Port in which two types of slips (slip A= Ward's flap; Slip B=Modified ward's flap) were present and every patient was allowed to take only one slip so that we plan for that particular type of mucoperiosteal flap.

After selection of patient into either groups, the standard preparation and draping was done and all surgeries were performed under supervision of senior surgeon experience more than 5 years, under local anesthesia by Conventional nerve block anesthesia of inferior alveolar nerve, lingual nerve and buccal nerve with two $1.8 \mathrm{~mL}$ cartridges of $2 \%$ xylocaine with epinephrine $1: 100,000$ (Medicaine; made in Korea) was given.

For group A, a standard full thickness mucoperiosteal flap (ward's flap) was raised by using sterile carbon steel surgical blade \#15 (Feather safety razor co. Ltd Japan). The incision was given mesial to the impacted lower third molar.

And for group B, a standard full thickness mucoperiosteal flap (Modified ward's flap) was given by incision mesial to second molar.

Using the straight elevator tooth was lifted; if tooth is retrieved, procedure was stop otherwise bone was removed with rosehead round bur in slow speed turbine form mesio-buccal and disto-buccal side with constant irrigation of $0.9 \%$ normal saline (Searle Ltd. Pakistan) then couplain straight elevator was used to lift the tooth after that any sharp bone was smoothen with curved bone filer then wound was closed with 3-0 Vicryl suture (Johnson \& Johnson; made in USA). Sterile folded gauze $(2 \times 2)$ was applied over the surgical wound to achieve compression and hemostasis for 30 minutes.

Standard antibiotics (Amoxi-clav 625mg BD) 
and painkillers (Ibuprofen 400mg TDS) were prescribed for 5 days.

At the end of the surgery, the flap design applied for the extraction of impacted lower third molar tooth and the duration of each operation (from the first extraction maneuver to the completion of the last suture), Pain, Swelling and Trismus ${ }^{13}$ were recorded on the proforma.

Every patient was called for follow up on the $3^{\text {rd }}$ day and $7^{\text {th }}$ day.

\section{RESULTS}

In this study mean age was found 27.93 years, with range of minimum 20 years and maximum 35 years. Table-I

Age $(n=64)$
Age (mean)

Standard deviation

Minimum

Maximum
27.93 years

3.93years

20 years

35 years
Table-I. Distribution of cases according to age $(n=64)$

Male were found in the majority $72.3 \%$ as compare to females $26.2 \%$. Table-II

\begin{tabular}{|l|c|c|}
\hline \multicolumn{1}{|c|}{ Gender } & Frequency & Percent \\
\hline Male & 47 & $72.3 \%$ \\
\hline Female & 17 & $26.2 \%$ \\
\hline
\end{tabular}

Table-II. Distribution of cases according to gender $(n=64)$

Preoperative pain measurement was done according VAS, $71.9 \%$ patients were found with mild pain, $9.4 \%$ were with moderate pain while $18.8 \%$ patients were without pain. Table-III

\begin{tabular}{|l|c|c|}
\hline \multicolumn{1}{|c|}{ VAS Scale } & Frequency & Percent \\
\hline No & 12 & $18.8 \%$ \\
\hline Mild & 46 & $71.9 \%$ \\
\hline Moderate & 6 & $9.4 \%$ \\
\hline
\end{tabular}

Table-III. Distribution of cases according to pain (According to VAS scale) $(n=64)$

Modified wards flap shows good efficacy regarding duration of third molar extraction as compare to Wards flap P-value 0.018. Results shows in Table-IV.

\begin{tabular}{|c|c|c|c|}
\hline Pre-operative & \multicolumn{2}{|c|}{ Flap Design } & P-Value \\
\hline Assessment & $\begin{array}{c}\text { A-Ward's } \\
\text { Flap }\end{array}$ & $\begin{array}{c}\text { B-Modified } \\
\text { Ward's Flap }\end{array}$ & \\
\hline$<10$ minutes & 13 & 15 & \\
\hline$<20$ minutes & 12 & 17 & 0.018 \\
\hline$<30$ minutes & 7 & 0 & \\
\hline
\end{tabular}

Table-IV. Flaps comparison according to duration of third molar extraction $(n=64)$

Modified ward's flap had showed less postoperative pain as compare to ward's flap p-value 0.022 , as well as no pain was found in 14 patients in modified ward's flap group and 6 patients noted without pain in ward's flap group, while moderate pain found in 4 patients in ward's flap group, while no moderate pain was found in modified ward's flap group. Table-V.

\begin{tabular}{|c|c|c|c|}
\hline $\begin{array}{c}\text { Post- } \\
\text { operative } \\
\text { Pain }\end{array}$ & $\begin{array}{c}|c| \\
\text { A-Ward's } \\
\text { Flap }\end{array}$ & $\begin{array}{c}\text { Besign } \\
\text { B-Modified } \\
\text { Ward's Flap }\end{array}$ & P-Value \\
\hline No pain & 6 & 14 & \\
\hline Mild pain & 22 & 18 & 0.022 \\
\hline Moderate pain & 4 & 0 & \\
\hline
\end{tabular}

Table-V. Post-operative pain according to Ward's flap versus modified ward's flap $(n=64)$

No significant difference was found between both groups on $3^{\text {rd }}$ postoperative day; according to Tragus to corner mouth, Lateral canthus to angle of mandible, Tragus to menton and Mouth opening. Results shows in Table-VI.

\begin{tabular}{|c|c|c|c|}
\hline Flap Design & Mean & SD & P-Value \\
\hline \multicolumn{3}{|l|}{ Tragus to Corner Mouth } & \multirow{3}{*}{0.427} \\
\hline A-Ward's Flap & 12.3563 & 1.14101 & \\
\hline B-Modified Ward's Flap & 12.1688 & 0.67463 & \\
\hline \multicolumn{3}{|c|}{ Lateral Canthus to Angle of Mandible } & \multirow{3}{*}{0.677} \\
\hline A-Ward's Flap & 11.9938 & 1.73743 & \\
\hline B-Modified Ward's Flap & 11.8188 & 1.60170 & \\
\hline \multicolumn{3}{|l|}{ Tragus to Menton } & \multirow{3}{*}{0.240} \\
\hline A-Ward's Flap & 14.7281 & 1.84535 & \\
\hline B-Modified Ward's Flap & 14.1938 & 1.75774 & \\
\hline \multicolumn{3}{|l|}{ Mouth Opening } & \\
\hline A-Ward's Flap & 43.6875 & 2.20611 & 0.382 \\
\hline B-Modified Ward's Flap & 43.2812 & 1.39664 & \\
\hline
\end{tabular}


No significant difference was noted in both groups on $7^{\text {th }}$ postoperative day; according to Tragus to corner mouth, Lateral canthus to angle of mandible, Tragus to menton and Mouth opening. Results shows in Table-VII.

\begin{tabular}{|l|l|l|l|}
\hline \multicolumn{1}{|c|}{ Flap Design } & Mean & SD & P-value \\
\hline Tragus to Corner Mouth & \multicolumn{3}{|c|}{} \\
\hline A-Ward's Flap & 12.0526 & .62126 & .462 \\
\hline B-Modified Ward's Flap & 11.8864 & .78576 & \\
\hline Lateral Canthus to Angle of mandible & \\
\hline A-Ward's Flap & 12.2632 & 1.40800 & \multirow{2}{*}{.026} \\
\hline B-Modified WARD'S flap & 11.3182 & 1.21052 & \\
\hline Tragus to Menton & 13.9211 & 1.96683 & \multirow{2}{*}{.732} \\
\hline A-Ward's Flap & 13.7273 & 1.63100 & \\
\hline B-Modified Ward's Flap & 44.9474 & 1.17727 & .366 \\
\hline A-Ward's flap & 44.5909 & 1.29685 & \\
\hline $\begin{array}{l}\text { B-Modified ward's flap } \\
\text { Table-VII. Comparison of flap according to swelling and } \\
\text { mouth opening after } 7^{\text {th }} \text { postoperative day (n=64) }\end{array}$ \\
\hline
\end{tabular}

\section{DISCUSSION}

Ward's and modified ward's incision are regularly used and it was observed that these incision offer tremendous visual access and can be sealed by means of a suture introduced between the buccal and lingual soft tissues alone. ${ }^{11,12}$ Likewise in this study we had compared Ward's and modified ward's flaps and we found good efficacy and less operative time in the modified ward's group as compare to ward's group. On the contrast to our study Desai $A$ et al $^{12}$ reported that Koener's envelope flap was found to be better in terms of post-operative healing in Ward's incision.

In this study mean age was found 27.93 years, with range of minimum 20 years and maximum 35 years. Koyuncu Bö et $\mathrm{al}^{13}$ reported that patients were between 18 and 40 years old, with the average age being 23.30 years. There were 29 female and 7 male patients. While we found male were found in the majority $72.3 \%$ as compare to females $26.2 \%$.

Preoperative pain measurement was done according VAS, $71.9 \%$ patients were found with mild pain, $9.4 \%$ were with moderate pain while $18.8 \%$ patients were without pain. Kumar $S$ et $\mathrm{al}^{14}$ informed that the effects displayed less hurt totals on comma incision side as paralleled to ward's incision side. Comparable results were found in the study of Nageshwar. Our results are not in correspondence with the outcomes of Gool et al as they have perceived that harshness in discomfort is not linked to the sort of incision. ${ }^{15}$ Modified ward's flap shows good efficacy regarding duration of third molar extraction as compare to Ward's flap P-value 0.018.

In our study modified ward's flap had showed less postoperative pain as compare to ward's flap $\mathrm{p}$-value 0.022 , as well as no pain was found in 14 patients in modified ward's flap group and 6 patients noted without pain in wards flap group, while moderate pain found in 4 patients in wards flap group, while no moderate pain was found in modified wards flap group.

Postoperative swelling is the consequence of trauma and infection. In this study no significant difference was found between both groups on $3^{\text {rd }}$ postoperative day; according to Tragus to corner mouth, Lateral canthus to angle of mandible, Tragus to menton and Mouth opening. In a previous study of Forsgren $\mathrm{H}^{\text {et }}{ }^{16}$ stated that swelling is most marked after 19 to 24 hours, and then lessens later about 7 days.

No significant difference was noted in both groups on $7^{\text {th }}$ postoperative day; according to Tragus to corner mouth, Lateral canthus to angle of mandible, Tragus to menton and Mouth opening. As well as Kumar $\mathrm{S}$ et $\mathrm{al}^{14}$ reported that massive swelling was not encountered in both groups on 7 th day, but $40 \%$ of the patients suffered enough pain in ward's incision assembly whereas only $13.33 \%$ had mild distension in modified ward's group.

\section{CONCLUSION}

This study concluded that both Ward's flap and Modified Ward's flap showed good efficacy, while duration of surgery and postoperative pain were significantly less in the Modified Ward's flaps as compared to Ward's flap. Larger sample size studies are required to evaluate more accurate findings.

Copyright $@ 13$ Nov, 2018. 


\section{REFERNCES}

1. Feitosa de Carvalbo R.W, Arruda de Araujo Filbo R.C, et al. Assessment of factors associated with surgical difficulty during removal of impacted maxillary third molars. J Oral \& Maxillofac Surg. 2013; 71;839-45.

2. Goyal M, Marya K, Jhamb A, Chawla S. et al. Comparative evaluation of surgical outcome after removal of impacted mandibular third molars using a Piezotome or a conventional handpiece: a prospective study. $\mathrm{Br} \mathrm{J}$ Oral \& Maxillofac Surg. 2012; 50;556-61.

3. Manclús V-G, Albiol, J-G. et al. Mandibular fractures related to surgical extraction of impacted lower third molars: A report of 11 cases. J Oral \& Maxillofac Surg. 2011; 69:1286-90

4. Kumar B S, Sarumathi T, Veerabahu M, Raman U et al. To compare standard incision and comma shaped incision and its influence in post-operative complications in surgical removal of impacted third molars. J Clin Diagn Res. 2013; 7;1514-8.

5. Adarsh D, Rushit P, Kiran D, et al. Comparison of two incision designs for surgical removal of impacted mandibular third molar: A randomized comparative clinical study. Contemp Clin Dent 2014; 5:170-4.

6. Yuasa $\mathrm{H} \mathrm{K}$, Sugiura M. Classification of surgical difficulty in extracting impacted third molars. $\mathrm{Br} J$ Oral \& Maxillofac 2002; 40:26-31.

7. Barreiro-Torres J, Diniz-Freitas M, Lago-Méndez L, Gude-Sampedro F, Gandara-Rey JM, García-García A. Evaluation of the surgical difficulty in lower third molar extraction. Med Oral Patol Oral Cir Bucal. 2010 Nov $1 ;$ 15(6): 869-74.

8. Diniz-Freitas M, Lago-Méndez L, Gude-Sampedro F, Somoza-Martin JM, Gándara-Rey JM, García-García A. Pederson scale fails to predict how difficult it will be to extract lower third molars. $\mathrm{Br} \mathrm{J}$ Oral \& Maxillofac Surg. 2007 Jan 31; 45(1):23-6.
9. Khanal $P$, Dixit $S$, Singh $R$, Dixit $P$, et al. Difficulty index in extraction of impacted mandibular third molars and their post-operative complications. $\mathrm{J}$ Oral Kathmandu Med College 2014; 15; 14-20

10. Akadiri $O A$, Obiechina AE. Assessment of difficulty in third molar surgery-a systematic review. J Oral \& Maxillofac Surg. 2009 Apr 30; 67(4):771-4.

11. Köymen R, Ortakoğlu K, Okçu KM, Altuğ HA, Aydıntuğ YS. Wound closure by skin traction. Turk J Med Sci 2002; 32: 179- 81.

12. Desai A, Patel R, Desai K, Vachhani NB, Shah KA, Sureja R. Comparison of two incision designs for surgical removal of impacted mandibular third molar: A randomized comparative clinical study. Contemporary clinical dentistry. 2014; 5(2):170.

13. Koyuncu bö, Zeytinoğlu $m$, Cetingül e. Comparison of two different flap techniques in the surgical removal of bilateral impacted mandibular third molars. Turkish Journal of Medical Sciences. 2013; 43(6):891-8.

14. Kumar S, Sarumathi T, Veerabahu M, Raman U. To compare standard incision and comma shaped incision and its influence on post-operative complications in surgical removal of impacted third molars. J Clin \& Diag Res: JCDR. 2013; 7(7):1514.

15. AV Van Gool JJ. Bosch T, Boering G. Clinical Consequences of complaints and complications after removal of the mandibular third molar. Int $\mathrm{J}$ Oral Surg 1977; 6:29-37.

16. Forsgren $H$, Heimdahl A, Johansson $B$, Krekmanov L. Effect of application of cold dressing on the postoperative course in oral surgery. Int J Oral Surg 1985; 14(3):223-228.

\begin{tabular}{|c|l|l|l|}
\hline \multicolumn{2}{|c|}{ AUTHORSHIP AND CONTRIBUTION DECLARATION } \\
\hline Sr. \# & \multicolumn{1}{|c|}{ Author-s Full Name } & \multicolumn{1}{|c|}{ Contribution to the paper } & Author=s Signature \\
\hline 1 & Ashook Kumar & $\begin{array}{l}\text { Principal investigator, data } \\
\text { collection. } \\
\text { Basic idea, Data collection. }\end{array}$ \\
\hline 2 & Anny Memon & $\begin{array}{l}\text { Suneel Kumar Panjabi } \\
\text { Methodology, References. }\end{array}$ \\
\hline 4 & Salman Shams & Resutls, Analysis \\
\hline
\end{tabular}

